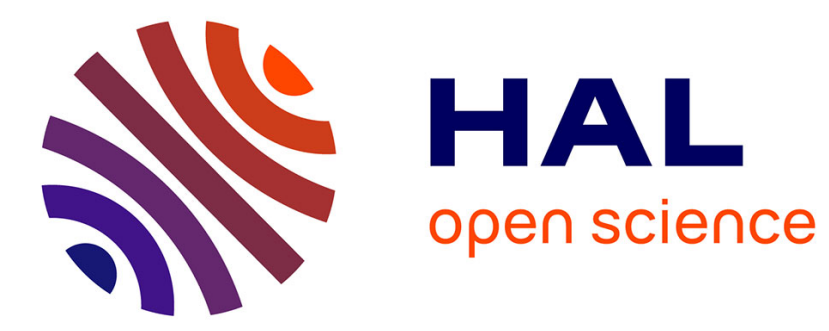

\title{
Silole derivatives: relationships between molecular arrangement and OLED efficiency.
}

Philippe Gerbier, Laurent Aubouy, Nolwenn Huby, Lionel Hirsch, Laurence Vignau

\section{> To cite this version:}

Philippe Gerbier, Laurent Aubouy, Nolwenn Huby, Lionel Hirsch, Laurence Vignau. Silole derivatives: relationships between molecular arrangement and OLED efficiency.. Proceedings of SPIE, the International Society for Optical Engineering, 2006, 6192, pp.61923A. 10.1117/12.667259 . hal-00187261

\section{HAL Id: hal-00187261 https://hal.science/hal-00187261}

Submitted on 14 Nov 2007

HAL is a multi-disciplinary open access archive for the deposit and dissemination of scientific research documents, whether they are published or not. The documents may come from teaching and research institutions in France or abroad, or from public or private research centers.
L'archive ouverte pluridisciplinaire HAL, est destinée au dépôt et à la diffusion de documents scientifiques de niveau recherche, publiés ou non, émanant des établissements d'enseignement et de recherche français ou étrangers, des laboratoires publics ou privés. 


\title{
Silole derivatives: relationships between molecular arrangement and OLED efficiency
}

\author{
Philippe Gerbier*a ${ }^{*}$ Laurent Aubouy ${ }^{\mathrm{a}}$, Nolwenn Huby ${ }^{\mathrm{b}, \mathrm{c}}$, Lionel Hirsch ${ }^{\mathrm{c}}$, Laurence Vignau ${ }^{\mathrm{b}}$, \\ ${ }^{\mathrm{a}}$ CMOS, UMR 5637, Université de Montpellier II, 34095 Montpellier Cedex 5, France \\ ${ }^{\mathrm{b}}$ PIOM, UMR 5501, ENSCPB, 33607 Pessac Cedex, France \\ ${ }^{c}$ IXL, UMR 5818, Université Bordeaux I, 33405 Talence Cedex, France
}

\begin{abstract}
The goal of the present study is to underline the relationships that may exist between the molecular arrangement in thin films and the OLED efficiency. For this purpose, we have synthesized three new silole derivatives with incrementally flexible structure to tune their packing ability. Moreover, these siloles were especially designed to possess both electronand hole-transporting properties in order to be used in single-layer OLEDs. This architecture was chosen since the absence of organic layers interfaces allows a better evaluation of the role of the molecular arrangement in the active layer. The examination of the EL properties gives evidences of the prominent role of the molecular organization on the OLED efficiency. A crystalline-like organization of the molecules allows high current density but low luminance efficiency since an excessive electron current flow is involved compared to the hole one, and the recombination rate is poor. On the contrary, disordered assemblies of molecules allows better performances by avoiding unfavorable $\pi$ stacking, while keeping good intermolecular orbital overlaps to support charge carrier transport. Thus single-layer devices based on silole 9 exhibit luminance efficiency as high as $0.75 \mathrm{Cd} / \mathrm{A}$ associated with both good chemical and film stabilities that are very promising applications for long life OLED application.
\end{abstract}

Keywords:

\section{INTRODUCTION}

Since Tang and VanSlyke made shine the first Organic Light Emitting Diode (OLED), ${ }^{1}$ much efforts have been made to improve these devices. Thus, multi-layers, ${ }^{2}$ doped, ${ }^{3}$ and phosphorescent ${ }^{4}$ OLEDs have been widely described and showed recently their limit in terms of durability because of interfacial or phase separation problems. ${ }^{5,6}$ Along with the implementation of further architectural refinements, the enhancement of the electroluminescence (EL) efficiency passes obviously through the synthesis of the new molecules possessing very dedicated capacities. For instance, good quantum yield, high charge mobility and adapted HOMO-LUMO levels are generally required to achieve good device output. ${ }^{7}$ Moreover, recent studies have also demonstrated the role of molecular organization on the luminescent properties. ${ }^{8} \mathrm{With}$ this in mind, we have designed a series of emissive silole derivatives having both the required electron- and holetransporting properties. These molecules were chosen since they intrinsically exhibit a good chemical stability along with optoelectronic and electron-transporting properties originating from an effective interaction between the $\sigma^{*}$-orbital of the silicon atom and the $\pi^{*}$-orbital of the butadiene moiety. ${ }^{9}$ The missing hole-transporting properties were added by just grafting arylamine side-groups to the central silole ring. As a result, single layer OLEDs based on these molecules show high performances, well above those observed when $\mathrm{Alq}_{3}$ is used as the active layer. ${ }^{10,11}$ We will report herein the implementation of a series of siloles having incrementally varied structures, $\pi$-conjugation, and intramolecular overlap properties with the main objective to elucidate some of the relationships that may exist between the molecular arrangements, the OLEDs efficiency.

\section{METHODOLOGIE}




\subsection{Device fabrication}

Devices of $c a .10 \mathrm{~mm}^{2}$ were fabricated on ITO-coated glass substrates (Merck, thickness $\approx 115 \mathrm{~nm}$, sheet resistance $\rho \approx 17 \Omega / \square$ ). A $50 \mathrm{~nm}$-thick layer of PEDOT-PSS was spun at $5000 \mathrm{rpm}$ on top of ITO and baked at $80^{\circ} \mathrm{C}$ for about 1 hour. On the PEDOT-PSS layer, all the organic compounds so as the cathodes were thermally evaporated under secondary vacuum $\left(10^{-6} \mathrm{mbar}\right)$ at about $1 \mathrm{~nm} / \mathrm{s}$ to a thickness of $60 \mathrm{~nm}$. Finally, a $80 \mathrm{~nm}$-thick Calcium capped by an Aluminum layer was evaporated through a shadow mask on top of the silole derivative. Current-voltage characteristics were recorded using a Keithley 2400 Sourcemeter and luminance-voltage with a photodiode placed under the OLED and coupled to a HP multimeter. Electroluminescence (EL) spectra were measured using an Ocean Optics PC2000 CCD spectrometer. All electroluminescent devices were kept and characterized in a glove box under nitrogen.

\subsection{Syntheses et compound characterizations}

Solvents were distilled prior to use. THF and ether were dried over sodium/benzophenone, and distilled under Argon. All the reactions were carried out under argon atmosphere. ${ }^{1} \mathrm{H},{ }^{13} \mathrm{C}$ and ${ }^{29} \mathrm{Si}$ NMR spectra were recorded on a Bruker Advance 200 DPX spectrometer, the FT-IR spectra on a Thermo Nicolet Avatar 320 spectrometer, the UV-visible spectra on a Secomam Anthelie instrument and the MS spectra on a Jeol JMS-DX 300 spectrometer. Synthesis and characterization of compounds $\mathbf{1}, \mathbf{5 a}, \mathbf{6 a}, \mathbf{7 a}$ were previously described. ${ }^{11}$ Organic glasses preparation for DSC studies: the sample of silole weas heated above its melting point and cooled at a rate of $30^{\circ} \mathrm{C} / \mathrm{min}$ to room temperature.

\subsection{1. p-2,2'-dipyridylaminophenyl-4-bromophenylether (2)}

White solid. Mp : $102^{\circ} \mathrm{C} .{ }^{1} \mathrm{H}$ NMR $\left(\mathrm{CDCl}_{3}, \delta, \mathrm{pmm}\right): 8.35\left(\mathrm{dd}, \mathrm{J}_{1}=7, \mathrm{~J}_{2}=2 \mathrm{~Hz}, 4 \mathrm{H}\right), 7.60\left(\mathrm{td}, \mathrm{J}_{1}=7, \mathrm{~J}_{2}=2 \mathrm{~Hz}, 4 \mathrm{H}\right)$,

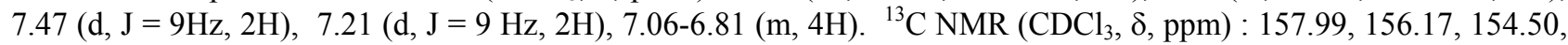
148.41, 140.33, 137.63, 132.74, 128.92, 120.82, 119.84, 118.15, 116.71, 115.95. HRMS (fab+, m-nitrobenzyl alcohol matrix) $\mathrm{m} / \mathrm{z}$ : calcd for $(\mathrm{M}+)_{22} \mathrm{C}_{16} \mathrm{~N}_{3} \mathrm{BrO} 418.0555$, found 418.0547 .

\subsubsection{1,1-Dimethyl-2,5-bis(8-para-biphenyldi-2-pyridylamine)silole (8)}

Bright yellow solid. Mp: $270^{\circ} \mathrm{C} .{ }^{1} \mathrm{H}$ NMR $\left(\mathrm{CDCl}_{3}\right): 8,45$, dd, $\mathrm{J}_{1}=6, \mathrm{~J}_{2}=2 ; 4 \mathrm{H} ; 7,62-7,54, \mathrm{~m}, 16 \mathrm{H} ; 7,42, \mathrm{~s}, 2 \mathrm{H} ; 7,29$, $\mathrm{m}, 4 \mathrm{H} ; 7,09-6,99, \mathrm{~m}, 8 \mathrm{H} ; 0,63$, s, $6 \mathrm{H} .{ }^{13} \mathrm{C} \mathrm{NMR}\left(\mathrm{CDCl}_{3}\right): 157,49 ; 148,15 ; 144,34 ; 143,41 ; 138,85 ; 138,65 ; 138,60$; 137,$93 ; 137,88 ; 128,81 ; 128,62 ; 127,43 ; 127,33 ; 118,59 ; 117,01 ;-2,69 .{ }^{29} \mathrm{Si}$ NMR $\left(\mathrm{CDCl}_{3}\right): 2,595$. HRMS $(\mathrm{m} / \mathrm{z})$ : calcd for $\left[\mathrm{C}_{50} \mathrm{H}_{40} \mathrm{~N}_{6} \mathrm{Si}\right] \mathrm{H}^{+}: 753,3162$ found 753,3128 .

\subsubsection{1,1-Dihexyl-2,5-bis(8-para-biphenyldi-2-pyridylamine)silole (9)}

Bright yellow solid. Mp: 83-84 ${ }^{\circ} \mathrm{C} .{ }^{1} \mathrm{H}$ NMR $\left(\mathrm{CDCl}_{3}\right): 8,33$, dd, $\mathrm{J}_{1}=6, \mathrm{~J}_{2}=2 ; 4 \mathrm{H} ; 7,70-7,60, \mathrm{~m}, 16 \mathrm{H} ; 7,49, \mathrm{~s}, 2 \mathrm{H}$; 7,30-7,25, m, 4H ; 7,14-7,02, m, 8H ; 1,35-0,81, m, 26 H. ${ }^{13} \mathrm{C} \mathrm{NMR}\left(\mathrm{CDCl}_{3}\right): 158,49 ; 148,77 ; 144,88 ; 143,62 ; 139,69$ ; 139,05;138,84;137,93;137,82;128,09; 127,83;127,48;127,14; 118,65;117,44;33,18;31,72;24,00;22,88 ; 14,$69 ; 13,64 .{ }^{29} \mathrm{Si} \mathrm{NMR}\left(\mathrm{CDCl}_{3}\right): 3,645$. Masse $(\mathrm{FAB}+\mathrm{m}-\mathrm{NBA}): \mathrm{MH}^{+}, \mathrm{m} / \mathrm{z}=893$.

Anal. Calcd for $\mathrm{C}_{60} \mathrm{H}_{60} \mathrm{~N}_{6} \mathrm{Si}: 80,67 \% \mathrm{C}, 6,77 \% \mathrm{H}, 9,40 \% \mathrm{~N}$ Found: $78,48 \% \mathrm{C}, 6,79 \% \mathrm{H}, 9,12 \% \mathrm{~N}$.

\subsubsection{1,1-Dimethyl-2,5-bis(8-para-diphenylether-di-2-pyridylamine)silole (10)}

Bright yellow solid. Mp: $173^{\circ} \mathrm{C} .{ }^{1} \mathrm{H}$ NMR $\left(\mathrm{CDCl}_{3}\right): 8,39$, dd, $\mathrm{J}_{1}=6, \mathrm{~J}_{2}=2 ; 4 \mathrm{H} ; 7,66-7,58, \mathrm{~m}, 18 \mathrm{H} ; 7,41, \mathrm{~s}, 2 \mathrm{H} ; 7,25-$ $6,94, \mathrm{~m}, 20 \mathrm{H} ; 0,62$, s, $6 \mathrm{H} .{ }^{13} \mathrm{C}$ NMR $\left(\mathrm{CDCl}_{3}\right): 158,29 ; 156,81 ; 155,57 ; 148,71 ; 144,71 ; 140,155 ; 139,31 ; 138,40$; 138,$15 ; 136,55 ; 131,29 ; 129,40 ; 128,59 ; 127,61 ; 127,01 ; 120,28 ; 119,89 ; 118,49 ; 117,57 ;-3,52 .{ }^{29}$ Si NMR $\left(\mathrm{CDCl}_{3}\right): 2,539$. Masse $(\mathrm{FAB}+, \mathrm{m}-\mathrm{NBA}): \mathrm{MH}^{+}, \mathrm{m} / \mathrm{z}=936$. Anal. Calcd for $\mathrm{C}_{62} \mathrm{H}_{48} \mathrm{~N}_{6} \mathrm{SiO}_{2}: 79,45 \% \mathrm{C}, 5,16 \% \mathrm{H}, 8,90$ $\% \mathrm{~N}$ Found: $77,23 \% \mathrm{C}, 5,64 \% \mathrm{H}, 7,96 \% \mathrm{~N}$.

\section{Results and discussion}

\subsection{Synthesis}

Originally synthesized by Braye and Hubel nearly 50 years ago, siloles experienced a wonderful rebirth in the 1990s with the implementation of new efficient synthetic methods allowing the introduction of various functional groups at 2,5-positions of the silacycle. ${ }^{12}$ However this procedure requires the presence of additional phenyl ring at the 3,4- 
positions, whose presence is detrimental to the luminescence quantum yield. This reason led us to consider the 2,5diarylsiloles series though they were less described due to their difficulty of synthesis. We reported in a previous communication a new synthetic route that allows the convenient preparation of siloles $\mathbf{6 a}$ and $\mathbf{6 b}$ that serves as starting material for a series of new 2,5-diarylsiloles (scheme 1). ${ }^{11}$ The linkage of the hole-transporting group was carried out through palladium-catalyzed Suzuki's cross-coupling reactions. Thus, bromine-substituted hole-transporting synthons 1 and $\mathbf{2}$ were synthesized by an Ullman's condensation in sealed tubes with an average yield of $83 \%$. They were converted to the corresponding boronic acids 3 and $\mathbf{4}$ by lithiation with n-BuLi followed by the addition of $\mathrm{B}(\mathrm{OMe})_{3}$. The hydrolysis, gave the boronic acids were used in the Suzuki's cross-coupling reaction in presence of $\mathrm{Pd}\left(\mathrm{PPh}_{3}\right)_{4}$ and sodium hydroxide. Siloles $\mathbf{8 , 9}$ and $\mathbf{1 0}$ were obtained with yields of 37,80 and 53\%, respectively as bright yellow solids.

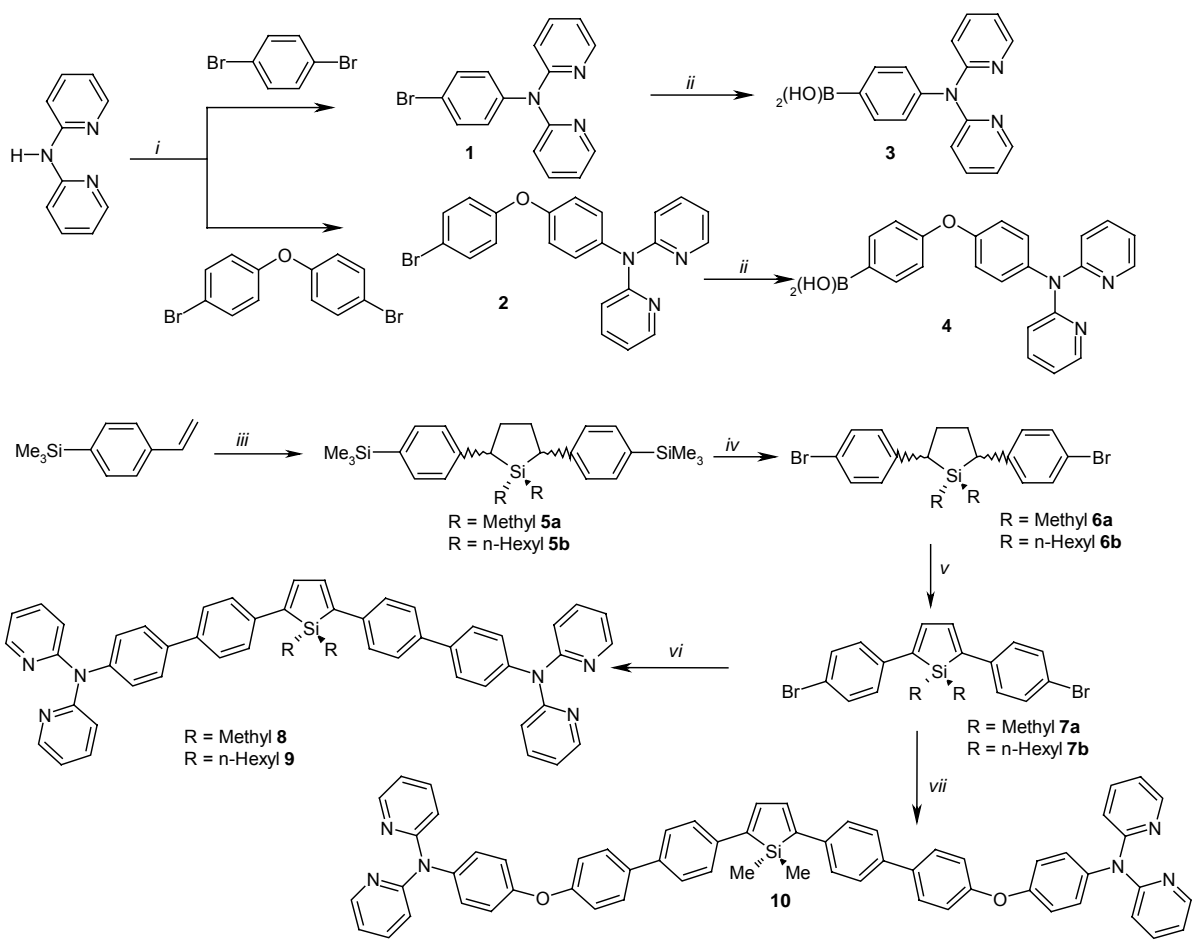

Scheme 1. (i) $\mathrm{CuSO}_{4}, \mathrm{~K}_{2} \mathrm{CO}_{3}, 205^{\circ} \mathrm{C}$, 6h ; (ii) 1) $n$-Buli and 2) $\mathrm{B}(\mathrm{OMe})_{3}$; (iii) Li, $\mathrm{R}_{2} \mathrm{SiCl}_{2}(\mathrm{R}=\mathrm{Me}, n$ - $\mathrm{Hex})$; (iv) $\mathrm{Br} 2$; (v) 1) Benzoyl peroxide, N-bromosuccinimide and 2) $\mathrm{CH}_{3} \mathrm{CO}_{2} \mathrm{H} / \mathrm{CH}_{3} \mathrm{CO}_{2} \mathrm{~K}$; (vi) 3, $\mathrm{Pd}\left(\mathrm{PPh}_{3}\right)_{4}, \mathrm{NaOH}$; $(v i i)$ 4, $\mathrm{Pd}(\mathrm{PPh})_{4}$, $\mathrm{NaOH}$.

\subsection{UV-visible absorption and photoluminescence properties}

UV-visible absorption and fluorescence spectra have been measured in diluted dichloromethane solutions. All the spectra are characterized by the presence of two intense absorption bands in the 280 and $420 \mathrm{~nm}$ regions (Table 1), the emission spectra show an emission peak around $515 \mathrm{~nm}$. As discussed previously, the absorption band observed at ca. $280 \mathrm{~nm}$ originates from $\pi-\pi^{*}$ transitions of the aryl groups, whereas the absorption band observed at $c a .420 \mathrm{~nm}$ is characteristic of $\pi-\pi^{*}$ transitions in the silole ring. ${ }^{12}$ When compared with the values reported for 1,1-dimethyl-2,3,4,5tetraphenyl silole TPS (absorption: $\lambda_{\max }=359 \mathrm{~nm}$, emission: $\lambda_{\max }=467 \mathrm{~nm}, \Phi_{\mathrm{em}}=0.0014$ ), and 1,1-dimethyl-2,5diphenyl silole DPS $\left(\lambda_{\max }=376 \mathrm{~nm}\right.$, emission: $\left.\lambda_{\max }=463 \mathrm{~nm}, \Phi_{\mathrm{em}}=0.29\right)$, the red-shift that is observed for all the new siloles both in absorption and emission is indicative of a substantial perturbation of the HOMO-LUMO levels. This perturbation is provided by both the more extended $\pi$-conjugation afforded by the biphenyl side-groups and by the presence of a terminal electronically active heteroatom $(\mathrm{N}, \mathrm{O})$. Moreover, as expected (see above), the removal of the phenyl rings at the 3,4-positions, associated to the extension of the conjugated backbone, involves a dramatic increase of the quantum yield that reaches values of $97 \%$ for 8 and 9 and $65 \%$ for $\mathbf{1 0}$. The relatively low value of $\Phi_{\mathrm{em}}$ that is 
observed with 10 originates from the disruption of the conjugation afforded by the bridging oxygen atom that lead, both the silole and the dipyridylamino chromophores to be considered as being electronically independent. In this situation the intramolecular energy transfer from the dipyridylamine sides groups to the silole ring, which is also responsible for the observation of such high quantum yields, appears to be less efficient. ${ }^{13}$ Finally, it is worthy to note that the absorption and emission properties of molecule $\mathbf{8}$ are identical as those of molecule 9, indicating that the organic groups (methyl vs hexyl) presents on the silicon atom don't affect the electronic properties of the siloles.

Table 1. UV and PL properties of siloles

\begin{tabular}{ccccc} 
Silole & $\boldsymbol{\lambda} \max \operatorname{Abs}(\mathbf{n m})$ & $\mathbf{L o g} \boldsymbol{\varepsilon}\left(\mathbf{m o l}^{-\mathbf{1}} \mathbf{. d m}\right)$ & $\boldsymbol{\Lambda m a x} \mathbf{P L}(\mathbf{n m})$ & $\boldsymbol{\Phi}_{\mathrm{em}}$ \\
\hline $\mathbf{8}$ & 419 & 5.63 & 524 & 0.97 \\
$\mathbf{9}$ & 421 & 5.62 & 524 & 0.97 \\
$\mathbf{1 0}$ & 416 & 5.45 & 508 & 0.65
\end{tabular}

\subsection{Molecular organization and thin film properties}

The molecular organization of vapor-deposited silole thin films $(50 \mathrm{~nm})$ onto PEDOT-PSS/ITO substrates were carried out by means of optical microscopy under polarized light, X-ray diffraction (XRD) and differential scanning calorimetry (DSC). Optical microscopy images (figure 1) show two different film morphologies: silole 8 forms highly featured film, whereas siloles $\mathbf{9}$ and $\mathbf{1 0}$ form rather homogeneous ones. The microscopic observation of the film formed with $\mathbf{8}$, under polarized light, shows that the featured zones are highly organized, as attested by the observation of birefringence. Despite of our efforts no diffraction peak, related to the observed molecular organization, was observed in the XRD patterns. Concerning siloles 9 and $\mathbf{1 0}$ no birefringence was observed, indicating that the films are amorphous. All these observations are confirmed by the DSC studies (Figure 2) carried out on the siloles as organic glasses (see experimental part). The curve obtained with silole 8 shows only a first order transition at $260^{\circ} \mathrm{C}$ corresponding to the melting point of a crystalline solid. By contrast, the curves obtained for siloles $\mathbf{9}$ and $\mathbf{1 0}$ show only second order transitions, corresponding to the glass transition $(\mathrm{Tg})$ at $99^{\circ} \mathrm{C}$ and $96^{\circ} \mathrm{C}$, respectively, corresponding to amorphous solids. Therefore, the introduction of either $n$-hexyl chains like in $\mathbf{9}$ or diphenylether bridges like in $\mathbf{1 0}$ induce the apparition of additional degrees of freedom that avoids long range molecular packing that is observed with the more rigid crystalline silole 8.

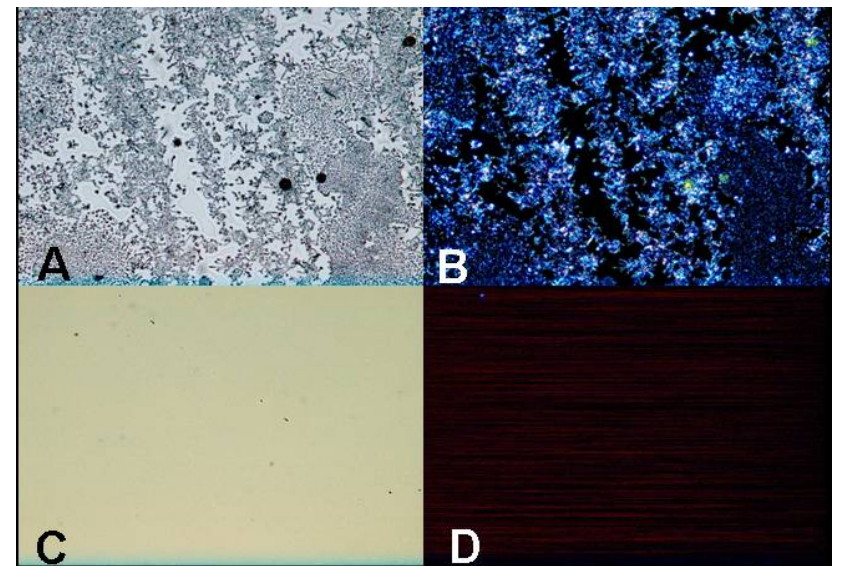

Figure 1. Optical micrographs of vapor-deposited silole films (50 nm) morphology on Pedot-PSS/ITO substrates. (A) Silole 8, and (C) siloles 9 or 10. Polarized optical microscopic images of (B) silole 8, and, (D) siloles 9 or 10. 


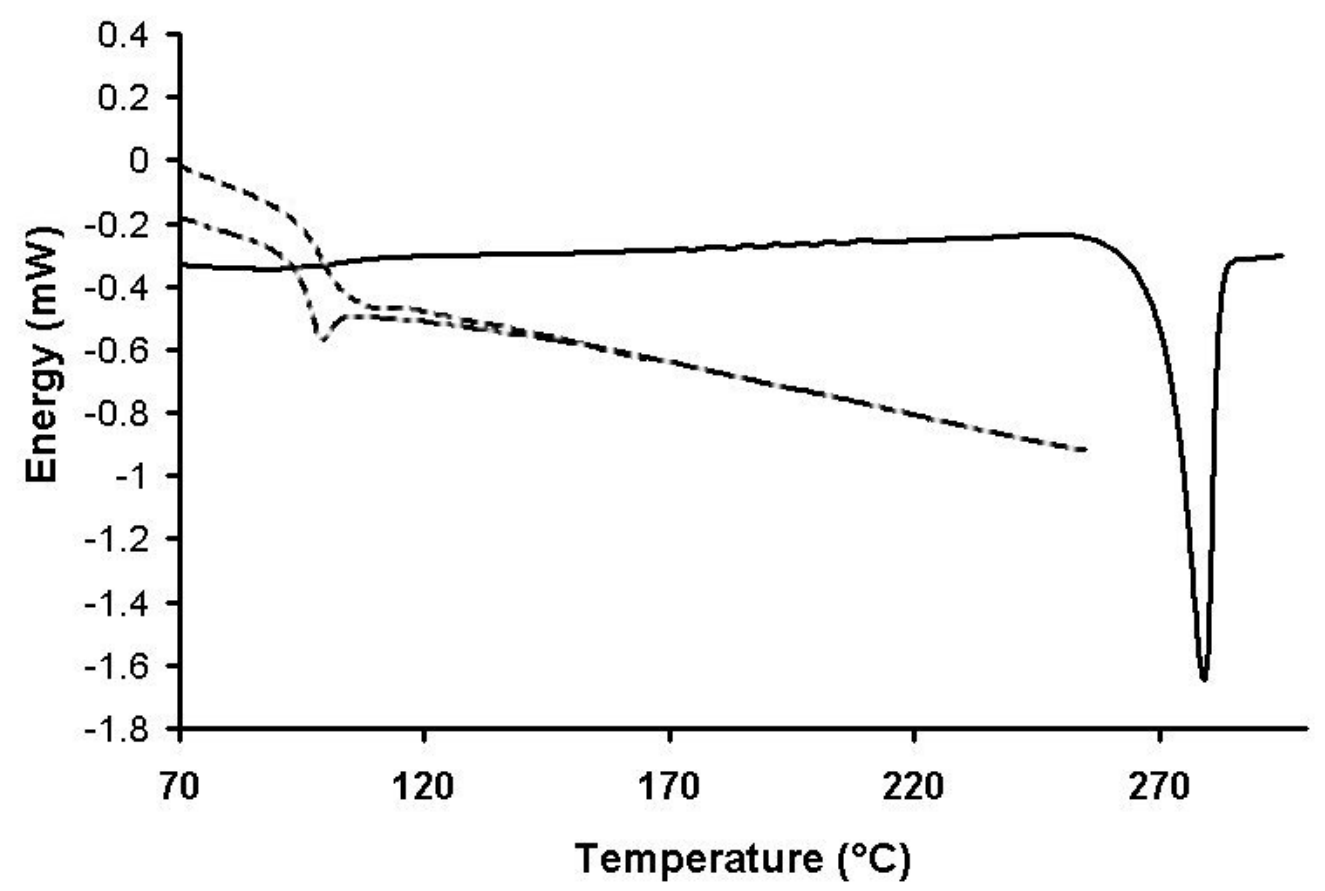

Figure 2. DSC analysis of siloles $8(-), 9(--)$, and $10(-\cdot)$ in the form of organic glasses.

\subsection{Electroluminescence properties}

On one hand, single layer devices were realized because it is of fundamental interest to understand the electrical behavior related to each silole. On the other hand, bilayer devices were elaborated to evaluate the performances of the silole derivatives as emitting layer. The structure of the single-layer devices has been systematically based on ITO/PEDOT for the anode and calcium for the cathode (Scheme 2). The emissive layer, sandwich between both electrodes, is always $50 \mathrm{~nm}$ thick in order to make coherent any comparisons. For bilayer devices, a hole transport layer, TPD (N,N'-diphenyl-N,N'-bis(3-methylphenyl)(1,1'-biphenyl)-4,4'-diamine), has been added, since the silole derivatives are known to displays more efficient electron than hole transporting properties. ${ }^{12}$ Thus, A, B and C are single-layer devices based on molecule 8, molecule 9 and molecule 10 respectively, D and E are bilayer devices based on molecule 9 and molecule $\mathbf{1 0}$, respectively.
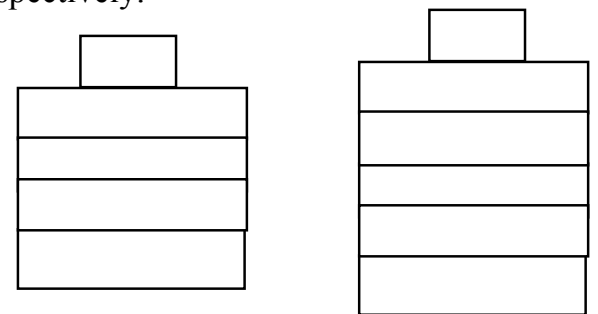

Scheme 2. Schematic representation of the investigated devices. A, B and C are single-layer devices based on molecule $\mathbf{8}$, molecule $\mathbf{9}$ and molecule $\mathbf{1 0}$ respectively. D and E are bilayer devices based on molecule $\mathbf{9}$ and molecule $\mathbf{1 0}$ as emitting layer and TPD as hole transport layer. 


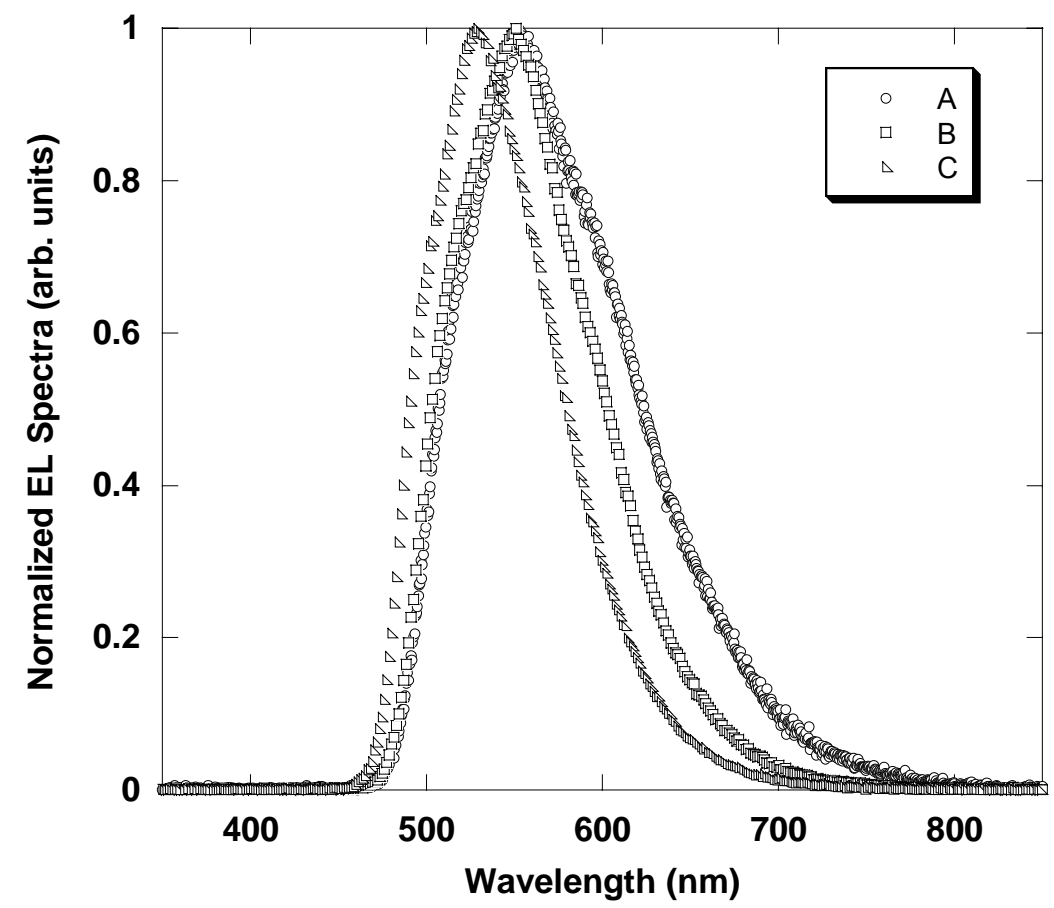

Figure 3. Normalized electroluminescence spectra of devices A, B and C.

All devices emit in the yellow-green region. The emission of $\mathbf{1 0}$ presents a $25 \mathrm{~nm}$ blue shift compared to both other siloles due to the conjugation disruption and/or heteroatom effect (see above). The shape of the EL spectra do not vary with the applied voltage and lead to (X;Y) CIE 1964 chromatic coordinates such as $(0.45 ; 0.53),(0.41 ; 0.56)$ and $(0.35$ ; 0.58) for A, B and C devices, respectively. Bilayer structures exhibit similar spectra (not shown), even though a weak shoulder is observed in particular for D around $600 \mathrm{~nm}$. This could be interpreted as recombinations at the TPD/9 interface, as it is often observed in multilayer structures. ${ }^{14}$ The bilayer devices lead to similar chromatic coordinates with $(0.42 ; 0.54)$ and $(0.36 ; 0.57)$ for $\mathrm{D}$ and $\mathrm{E}$ respectively.

Current density-voltage $(J-V)$ and luminance-voltage $(L-V)$ characteristics are presented in figure 4 . Device A exhibits a high threshold voltage at $11 \mathrm{~V}$, twice higher than for both $\mathrm{B}$ and $\mathrm{C}$. Values of $90 \mathrm{Cd} / \mathrm{m}^{2}$ at $17 \mathrm{~V}, 850 \mathrm{Cd} / \mathrm{m}^{2}$ at $9 \mathrm{~V}$ and $500 \mathrm{Cd} / \mathrm{m}^{2}$ at $9 \mathrm{~V}$ are reached for device A, B and C respectively. Actually, that can be explained by the recombination efficiency of each emissive compound. Indeed for a luminance of $100 \mathrm{Cd} / \mathrm{m}^{2}, 8$-based device displays $200 \mathrm{~mA} / \mathrm{cm}^{2}$, whereas $20 \mathrm{~mA} / \mathrm{cm}^{2}$ and $40 \mathrm{~mA} / \mathrm{cm}^{2}$ are observed for devices $\mathrm{B}$ and $\mathrm{C}$ respectively. The high current density and low luminance efficiency for device A should be connected to the supramolecular organization of the organic thin film that induces long-range $\pi$-stacking. As a consequence, an excessive electron current flow is involved compared to the hole one and the recombination rate is poor. On the contrary, B offers better performances, indicating that hexyl groups avoid unfavorable $\pi$-stacking, while keeping good intermolecular orbital overlaps to support charge carrier transport. Similar conclusions can be drawn for molecule $\mathbf{1 0}$ (device C), in spite of lower efficiency than for device B at the same current density. 


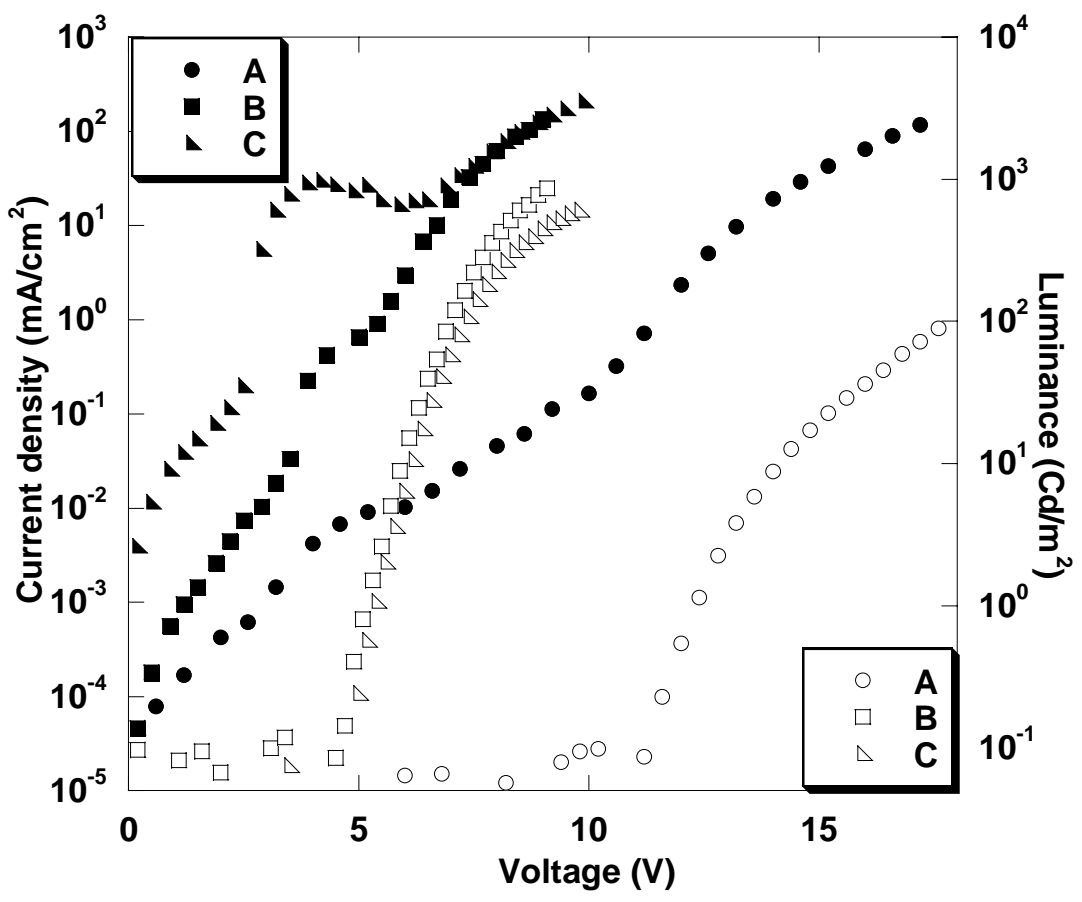

Figure 4.Current density-voltage and luminance-voltage characteristics for single-layer devices based on the three silole derivatives as emitting layer. Open and full symbols correspond to the luminance and current density respectively.

Considering the promising results obtained with siloles 9 and $\mathbf{1 0}$ (devices D and E respectively), bilayer devices have been realized to improve the performances. Table 2 summarizes the electrical properties and compares with those of single-layer devices. Threshold voltage $V_{t h}$ of both OLEDs is reduced indicating a more efficient hole injection, but their behavior differs. While the efficiency of device $\mathrm{E}$ is three times the one of device $\mathrm{C}$, performances of devices $\mathrm{B}$ and $\mathrm{D}$ are almost identical. For molecule $9,100 \mathrm{Cd} / \mathrm{m}^{2}$ are reached for the same current density in single-layer and bilayer devices. On the contrary, the insertion of the hole-transporting layer in the device based on the molecule $\mathbf{1 0}$ divides the current density per four to reach $100 \mathrm{Cd} / \mathrm{m}^{2}$ on account to a better charge balance. Indeed, the intermolecular cooperation in molecule $\mathbf{1 0}$ seems to significantly enhance the mobility of holes between emissive centers. Complementary experiments will be carried out in order to specific this point.

Table 2. Summary of the performances measured for bilayer and single-layer devices.

\begin{tabular}{ccccc} 
Device & $\mathbf{V}_{\text {th }}(\mathbf{V})$ & $\mathbf{L} \max \left(\mathbf{C d} / \mathbf{m}^{2}\right)$ & $\mathbf{C d} / \mathbf{A} \max$ & $\mathbf{I m} / \mathbf{W} \max$ \\
\hline B & 4.8 & 1000 & 0.75 & 0.35 \\
$\mathbf{C}$ & 4.8 & 630 & 0.45 & 0.12 \\
$\mathbf{D}$ & 4.0 & 2220 & 1.10 & 0.40 \\
$\mathbf{E}$ & 3.8 & 2000 & 1.30 & 0.60
\end{tabular}

\section{Conclusion}

Three new silole derivatives, especially designed for single-layer OLED structures, were presented. They were obtained by a new synthetic route and possess very strong quantum yields in solution on account to both the removal of the phenyl rings at the 3,4-positions, which are inherent to the Tamao's procedure, and to the extension of the conjugated backbone. Starting from silole 8, which displays a strong ability to crystallize in thin films, we have chemically modified its structure to disfavor the packing of the molecule and therefore the $\pi$-stacking. For that, we have either grafted long-chain alkyls on the silicon atom to reduce the Van der Waals' interactions (silole 9) or introduced conformational disorder by inserting an ether bridge into the conjugated rigid system (silole 10). These modifications 
allowed us to obtain good quality amorphous films by vapor deposition onto PEDOT-PSS/ITO substrates. The examination the EL properties of the devices fabricated with these compound gives evidences of the prominent role of the molecular organization on the OLED efficiency. A crystalline-like organization of the molecules allows high current density but low luminance efficiency since an excessive electron current flow is involved compared to the hole one, and the recombination rate is poor. On the contrary, disordered assemblies of molecules allows better performances by avoiding unfavorable $\pi$-stacking, while keeping good intermolecular orbital overlaps to support charge carrier transport. Thus single-layer devices based on silole 9 exhibit luminance efficiency as high as $0.75 \mathrm{Cd} / \mathrm{A}$ associated with both good chemical and film stabilities that are very promising applications for long life OLED application.

\section{Aknowledgements}

This work was supported by the French CNRS and the Universite Montpellier II. PG and LA are indebted to the Région Languedoc-Roussillon for its financial support and for the award of a $\mathrm{PhD}$ Thesis. $\mathrm{LH}, \mathrm{LV}$ and $\mathrm{NH}$ are grateful to the Région Aquitaine for its financial support.

\section{References}

1. C.W. Tang, S. A. VanSlyke, J. App. Phys., 51(12), 913, 1987.

2. C. Adachi, T. Tsutsui, S. Saito, Appl. Phys. Lett., 56(9), 799, 1990.

3. C.W. Tang, S. A. VanSlyke, C. H. Chen, J. App. Phys., 65(9), 3610, 1989.

4. M. A. Baldo, D. F. O’Brien, Y. You, A. Shoutikov, S. Sibley, M. E. Thompson, S. R. Forrest, Nature, 395, 151, 1998.

5. D.Y. Kondakov, J. R. Sandifer, C. W. Tang, R. H. Young, J. Appl. Phys., 93(2), 1108, 2003.

6. J. R. Gong, L. J. Wan, S. B. Lei, C. L. Bai, X. H. Zhang, S. T. Lee, J. Phys. Chem. B., 109, 1675, 2005.

7. U. Mitschke, P. Bauerle, J. Mater. Chem., 10, 1471, 2000.

8. M. Brinkman, G. Gadret, M. Muccini, C. Taliani, N. Masciocchi, A. Sironi, J. Am. Chem. Soc., 122, $5147,2000$.

9. S. Yamaguchi, K. Tamao, J. Chem. Soc., Dalton Trans., 3693, 1998.

10. M. Uchida, T. Izumizawa, T. Nakano, S. Yamaguchi, K. Tamao, K. Furukawa, Chem. Mater., 13, $2680,2001$.

11. L. Aubouy, P. Gerbier, N. Huby, G. Wantz, L. Vignau, L. Hirsch, J. M. Janot, New J. Chem., 28, $2004,1086$.

12. S. Yamaguchi, T. Endo, K. Furukawa, T. Izumizawa, K. Tamao, Chem. Eur. J., 6(9), 1683, 2000.

13. L. Aubouy, N. Huby, G. Wantz, L. Vignau, Ch. Guérin, P. Gerbier, C. R.. Chimie, 8, 1262, 2005.

14. L.C. Palilis, A.J. Mäkinen, M. Uchida, Z.H. Kafafi, Applied Physics Letters, 82, 2209, 2003. 